\title{
Erratum to: Spectral Discretization of the Axisymmetric Vorticity, Velocity and Pressure Formulation of the Stokes Problem
}

\author{
Nehla Abdellatif • Nejmeddine Chorfi • Sihem Trabelsi
}

Received: 1 April 2011 / Published online: 19 April 2011

(C) Springer Science+Business Media, LLC 2011

\section{Erratum to: J Sci Comput \\ DOI 10.1007/s10915-010-9446-2}

In the original publication, the project number was omitted from the Acknowledgement. The Acknowledgement should read as follows: "The authors extend their appreciation to the Deanship of Scientific Research at King Saud University for funding the work through the research group project No RGP-VPP-087."

The online version of the original article can be found under doi:10.1007/s10915-010-9446-2.

N. Abdellatif

Ecole Nationale des Sciences de l'informatique/LAMSIN, Campus universitaire El Manar, B.P. 244 El Manar II, 2092, Tunis, Tunisia

e-mail: nahla.abdellatif@ensi.rnu.tn

N. Chorfi $(\bowtie)$

Department of Mathematics, College of Science, King Saud University, P.O. Box 2455, Riyadh 11451, Saudi Arabia

e-mail: nchorfi@ksu.edu.sa

S. Trabelsi

Institut préparatoire aux études d'ingénieurs El Manar, Campus universitaire El Manar, B.P. 244 El

Manar II, 2092, Tunis, Tunisia

e-mail: trabel_sihem@yahoo.fr 